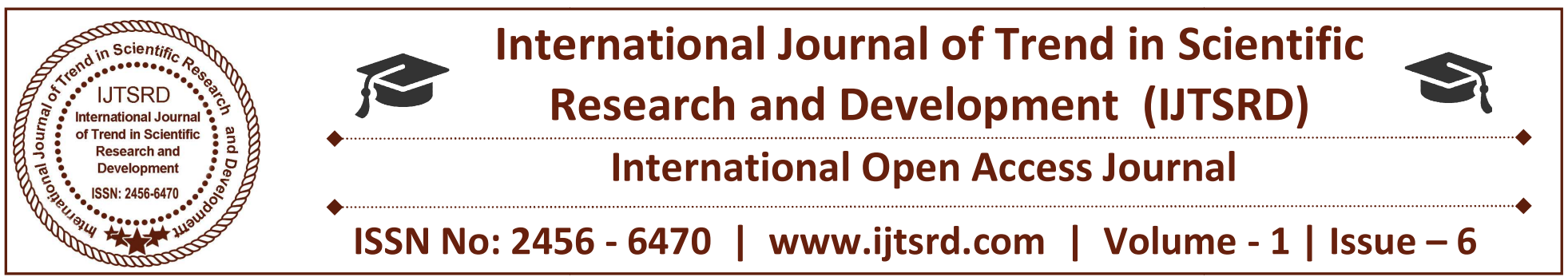

\title{
Smart Garbage Monitoring System : Present And Future
}

\author{
Mr. Gopal V. Masane \\ Dept. of ENTC Engg. Mauli College of \\ Engg. \& Tech., Shegaon, Maharashra \\ Miss Roshani A. Naphade \\ Dept. of ENTC Engg. Mauli College of \\ Engg. \& Tech., Shegaon, Maharashra
}

\author{
Mr. Dnyaneshwar R. Raut \\ Dept. of ENTC Engg. Mauli College of \\ Engg. \& Tech., Shegaon, Maharashra \\ Mr. Nilesh M. Verulkar \\ Dept. of ENTC Engg. Mauli College of \\ Engg. \& Tech., Shegaon, Maharashra
}

\begin{abstract}
The main objective of this paper is to observe the trash can and maintain the surroundings sensible and clean. Today folk's square measure victimization additional merchandise as well as food things, industrial merchandise, medicines and, plastic materials. Once expiration of those things they're place it into a trash can for disposal. While not correct maintenance of dustbins, these expiration things will produce epidemic diseases among folks and pollution to the atmosphere. that the dustbins at cities, home, industries and hospitals have to be compelled to be maintained properly to make sure cleanliness.In this system we have a tendency to square measure attending to use Raspberry-Pi, Ultrasonic sensing element and Flame sensing element. The vision of our project is to form the environment clean in sensible method.
\end{abstract}

Keywords: Internet of Thing (IoT), Global System for Mobile Communication (GSM), Ultrasonic Sensor, Flame Sensor, Humidity Sensor, Load Sell

\section{INTRODUCTION}

In recent due to rapid growth of population disorganization of city government a lack of public awareness \& limited fund for program of waste management garbage disposal become a cause of concern in the world. A very large amount of waste generated is disposal by means which has an effect on the environment. The Central Public Health \& Environment Engineering Organization has estimated that waste produced in India as much as 1.5 pound per person per day. This amount is low compared to the 5 pound of waste produced per person per day in United State. But the US population was close to 310 million in June 2008, whereas India's population was 1.2 billion. According to these statistics India could be producing as much as 28 million tons more waste than US per year. The common way of disposal of waste \& garbage is unplanned and uncontrolled openly dumped on the roads. This method is unhygienic and harmful to human, plant and animal .This unhygienic way of dumping waste can generate liquid leach ate which may pollute underwater resources; causes a harmful disease. Most of the viruses and bacterial infection develop in unclean environment

A big challenge in the metro cities is waste and garbage management. Hence, smart waste management is a system which can solve or reduce at least to minimum level. Our PM Shri Narendra Modiji introduced the concept of implementing about 100 smart cities in India. "Swachh Bharat Mission" was initiated to clean environment. Amount of waste produced is depend on two factors first, the population of given area and second is consumption patterns. In smart waste and garbage management system, the smart dustbins are connected to the 
internet by which we get real time information of the dustbins. The smart waste and garbage management system uses the IOT. The IOT is nothing but the "Thing (Devices) that are connected to internet and sometimes these devices can be controlled from internet is commonly known as IOT.

\section{CONCEPT OF IOT}

The Internet of Things (IOT) is a worldwide network of intercommunicating devices. It integrates the ubiquitous communications, pervasive computing, and ambient intelligence.IOT is a vision where "things", especially everyday objects, such as all home appliances, furniture, clothes, vehicles, roads and smart materials, etc. are readable, recognizable, locatable, addressable and/or controllable via the Internet. Internet of Things will connect the world's objects in both a sensory and intelligent manner through combining technological developments in item identification ("tagging things"), sensors and wireless sensor networks ("feeling things"), embedded systems ("thinking things") and nanotechnology ("shrinking things").

This will provide the basis for many new applications, such as Energy monitoring, transport safety systems or building security. This vision will surely change with time, especially as synergies between Identification Technologies, Wireless Sensor Networks, Intelligent Devices and Nanotechnology will enable a number of advanced applications. Innovative use of technologies such as RFID, NFC, ZigBee and Bluetooth, are contributing to create a value proposition for stakeholders of IOT. In 2005, Wal-Mart and the U.S. Department of Defense demanded that their major contractors and suppliers mark their shipments with RFID tags for inventory control. The explosion of the RFID market in 2005 marked the dawn of the thinking about the Internet of Things. [7]

\section{PROBLEM DEFINATION}

As we see many times the dustbin are get over flown and concern person do not get the information on a time and due to which unconscious condition form in the surroundings, at the same time bad smell come out from waste and spread out in surrounding. Due to the unclean environment some harmful diseases easily spreadable in given locality. The existing system used for cleaning the dustbin is not effective and which has some disadvantages which as follows-
Less effective and time consuming

Cost is very high

Environment become unhygienic

Because of bad smell of garbage human beings may cause illness

More traffic and noise due to truck used to clean the dustbin

\section{RELATED WORK}

The waste and garbage management in metro cities has to be effectively and efficiently implemented. The various method and system put forward and some of them are already implemented. But it can't to be considered as effective. So a survey was done among different method and system and this survey paper include survey among different system for smart waste and garbage monitoring in metro cities using IoT.

In [2], Raspberry-pi, flame sensor and ultrasonic sensor using form an integrated system for monitoring the garbage level in dustbin remotely. The sensors are placed in dustbin placed at public places. The ultrasonic sensor senses the level of garbage in bin and when it reaches to threshold level it send the signal to raspberry-pi. The raspberry-pi is connected to internet and it the message to respective person and control room.

Another method for waste management is introduced in [3] as follows: This system is implemented using microcontroller, ultrasonic sensor, weight sensor, RF Id card reader module. The ultrasonic sensor sense the level of garbage and send the signal to microcontroller. The microcontroller sends the id of that dustbin to Municipal Corporation Server [MCS]. Through Municipal Corporation server the message is goes to control room and concern person.

In [4], the proposed system form by using 8051 micro-controller, RF module, IR sensors, RF transmitter and receiver, Intel Galileo Gen 2. The bin interfaced with micro- controller based IR sensor and RF module. The IR sensor detect the level of garbage in dustbin and send signals to the micro-controller, the same signal encoded and send through RF transmitter to Central System (Intel Galileo). At central system it is received by $\mathrm{RF}$ receiver and decoded. Internet connection is enabled through LAN cable from modem. The data is received, analyzed and processed 
in the cloud which displays the status of waste and garbage in the bin on the GUI on web browser.

The system proposed by [6] assures the cleaning of dustbins soon when the garbage level reaches in its threshold level. In this proposed system they used ArduinoUno, GSM module, Ultrasonic sensor. The ultrasonic sensor detects the level of garbage in bin. If it reach at threshold level send signal to ardunio uno, it control the overall system. The ardunio uno send signal to GSM which is used for wireless communication with control room and cleaner.

\section{PROPOSED HARDWARE}

\section{1) Raspberry-pi-:}

The Raspberry-pi could be a low value, credit-card sized laptop that plugs into a laptop monitor or TV, and uses a regular keyboard and mouse. It's capable of doing everything

you'd expect a PC to try and do. The Raspberry Pi has the flexibility to act with the outside world, and has been employed in a large array of digital maker comes, from music machines and parent detectors to weather stations and tweeting birdhouses with infrared cameras.

\section{2) Ultrasonic Sensor-:}

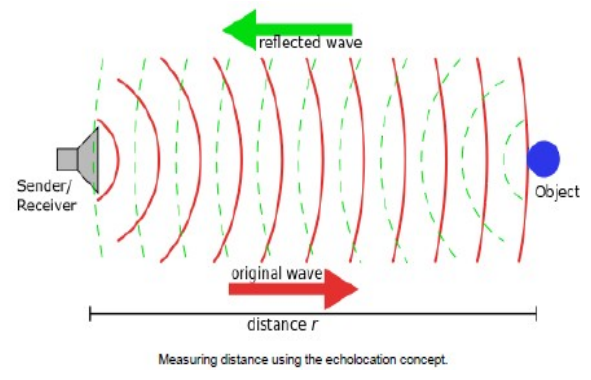

The basic regulation is victimization $\mathrm{I} / \mathrm{O}$ trigger for a minimum of $10 \mu \mathrm{s}$ high level signal, the module automatically sends $40 \mathrm{kHz}$ pulse and detects if there's a pulse mirrored back. If the signal reflects back within the sort of high pulse, then the time taken between the instance of causation trigger pulse and the reception of echo pulse is that the total time of high output $\mathrm{I} / \mathrm{O}$ period. It uses electrical-mechanical energy transformation to live distance between the device and target object.

\section{3) GSM Modem-:}

GSM electronic equipment includes an offer voltage vary of concerning three. $8 \mathrm{~V}-4.1 \mathrm{~V}$. It's an occasional power consumption device (1.5mA) with sleep mode.

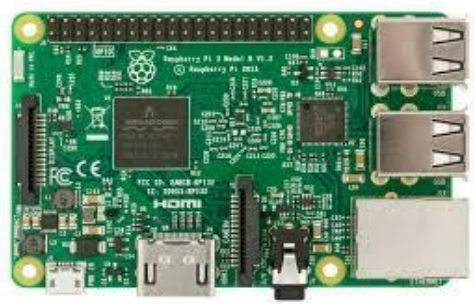

It additionally has operational temperature from $-40^{\circ} \mathrm{C}$ to $85^{\circ} \mathrm{C}$. Tourge simply connected to varied devices, its communication interfaces like interface, RS232 USB. The power offer circuit has additionally been provided on GSM module.

\section{4) Humidity Sensor-:}

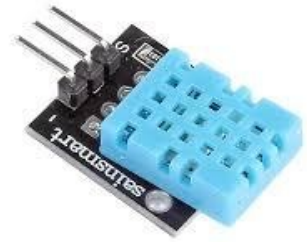

The temperature and humidity sensor have to be used to distinguish between dry and wet waste. For this purpose DHT11 sensor will be used. Depending upon the output temperature, dry and wet waste would be differentiated. The DHT11 is a high precision digital humidity and temperature sensor. It uses a capacitive humidity sensor and a thermistor to measure the surrounding air, and spits out a digital signal on the data pin. Sensor will only get new data from it once every 2 seconds. It will be good for $0-100 \%$ humidity readings with $2-5 \%$ accuracy and for -40 to $80^{\circ} \mathrm{C}$ temperature readings $\pm 0.5^{\circ} \mathrm{C}$ accuracy.

\section{5) Load Sell-:}

The load cell needs to be used to weigh dustbin. A load cell is a transducer that creates an electrical signal whose magnitude is directly proportional to the force being measured. The load cell ranges from few grams to $200 \mathrm{~kg}$. The electrical signal output will be typically in the order of a few mill volts and will require amplification before it can be used. The HX711 load cell amplifier has to be used to get measurable data out from a load cell. 


\section{6) Wi-Fi-:}

Major part of this system depends upon the working of the Wi-Fi module. Wi-Fi Module helps us to send the details of the dustbin at the receiver side. The controller gives the details to the transmitter module (Wi-Fi module). At the receiver section a mobile handset is needed to be connected to the Wi-Fi router so the details of the garbage bin is displayed on the web page and a mail notification (like email) will be sent to the respective Municipal / Government authority person.

\section{7) LCD Display-:}

A liquid crystal display (LCD) is a thin, flat display device made up of any number of color or monochrome pixels arrayed in front of a light source or reflector. Each pixel consists of a column of liquid crystal molecules suspended between two transparent electrodes, and two polarizing filters, the axes of polarity of which are perpendicular to each other. Without the liquid crystals between them, light passing through one would be blocked by the other. The liquid crystal twists the polarization of light entering one filter to allow it to pass through the other. Many microcontroller devices use 'smart LCD' displays to output visual information.

\section{PROPOSED SOFTWARE}

\section{1) RASPBIAN OS-:}

Raspbian is a free operating system based on Debian optimized for the Raspberry-Pi hardware. An operating system is the set of basic programs and utilities that make your Raspberry Pi run. However, Raspbian provides more than a pure OS: it comes with over 35,000 packages; pre-compiled software bundled in a nice format for easy installation on your Raspberry Pi.

\section{2) PYTHON-:}

Python is an interpreter, interactive, object-oriented programming language. It is often compared to Tcl, Perl, Scheme or Java. It is a scripting language like php or asp for developing applications Python is an interpreter, object- oriented, high-level programming language with dynamic semantics. Programming language consist some specific code which are require to write any program in the programming language. Because of computer programs are written in by which language is called Computer programming language.

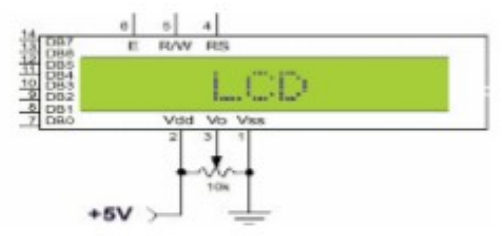

\section{PROPOSED SYSTEM}

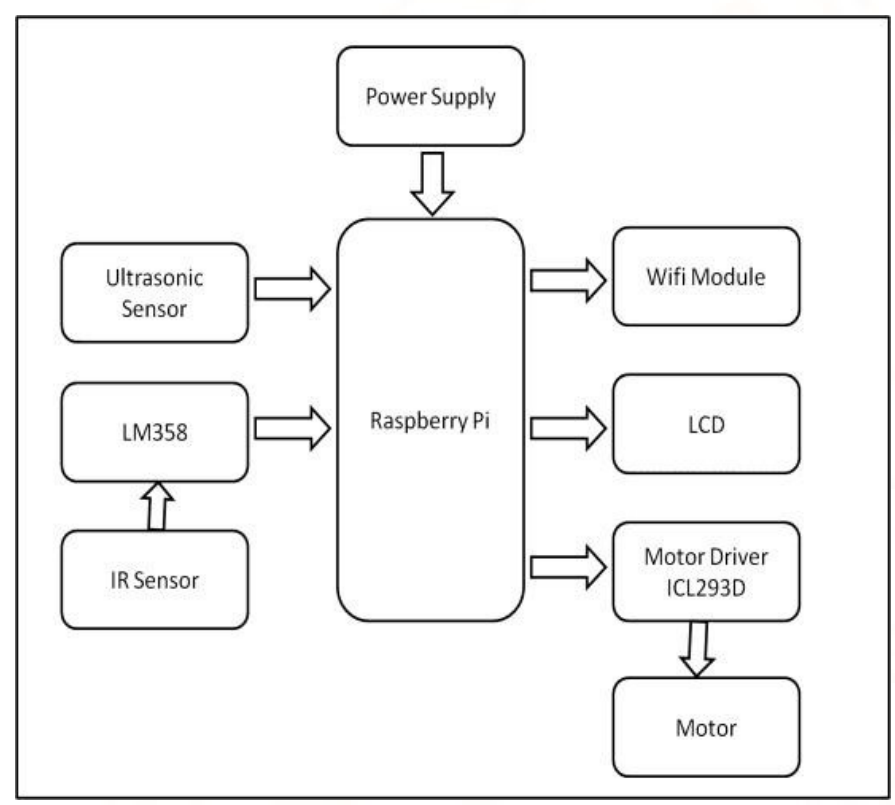

Fig. 1: Block diagram of the system

The Block diagram shows the different component used in the Smart Dust bin System is Power Supply, Ultrasonic Sensor, IR Sensor, Motor, Using Internet and Wi- Fi Module. Ultrasonic Sensor is connected in dustbin it is used to detect the level of dustbin where dustbin is full or empty.

Here we are using 5 different Ultrasonic sensors :

1. Dustbin empty $25 \%$ (when first level sensor gives output).

2. Dustbin half $50 \%$ (when first and second level sensor gives output).

3. Dustbin half $75 \%$ (when first, second and third level sensor gives output).

4. Dustbin full $90 \%$ (when all four level sensors give output).

5. Dustbin heavy when threshold level of dustbin is crossed (ultrasonic sensor gives output).

IR sensor consists of IR LED (Transmitter and Receiver) and OP-AMP LM358 IC. When IR sensor emits the radiation, it reaches the object and some of 
the radiation reflects back to the IR receiver. Based on the intensity of light its output is defined. Here it is used as an object detection sensor.

In our system Motor is used for opening and closing of the Garbage bin lid. This can be done by forward and reverse direction rotation of motor. For smooth running, good speed regulation and operating of motor Drive IC L293D is used. In all condition we receive data on web portal using Wi-Fi module and the same thing will be displayed on LCD screen connected to the Garbage Bin. Wi- Fi Module helps us to send the details of the dustbin at the receiver side

\section{FLOW CHART}

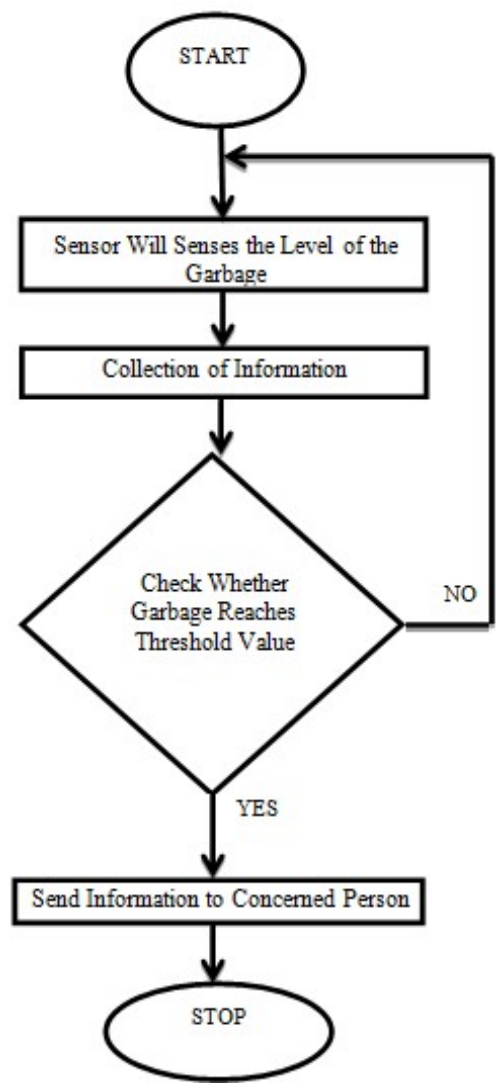

\section{ADVANTAGES AND DISADVANTAGES}

\section{A) ADVANTAGES:}

1. The garbage will be collected on time-to-time basis.

2. There would not be any bad smell around the bin.

3. Real time notification to collect the garbage.

4. Saving on fuel consumption, thus reducing the threat to the environment.
B) DISADVANTAGES:

1. It requires a well structured hardware.

2. The onetime cost of installation will be higher than the present technique.

3. Need of good sensor for regular sense dust.

\section{APPLICATION}

$>$ Domestic
$>$ Hotels
$>$ Homes
$>$ Malls
$>$ Railway Station
$>$ Bus Stop
$>$ Gardanes
$>$ Colleges

\section{CONCLUSION}

This paper shows how the smart waste and garbage management using IoT can be implemented. This proposed system assures the collection of garbage and waste soon when the waste level reaches its threshold level. The system will thus provide correct information; increase the efficiency of the system. The real-time monitoring of the garbage level with the help of sensors and wireless communication will reduce the total number of trips required of garbage collection vans (GCV) and thus, will reduce the total expenditure required to garbage and waste collection.

This system has various features such as durability, affordability, accuracy, prevention against damage and maintenance issues are addressed when these smart dustbins are designed. This Smart Dustbin can contribute a lot towards clean neat and hygienic environment in building a smart city.

After the garbage level reaches the threshold value. The intimation will be send to the concerned person either via mobile or through webpage. 


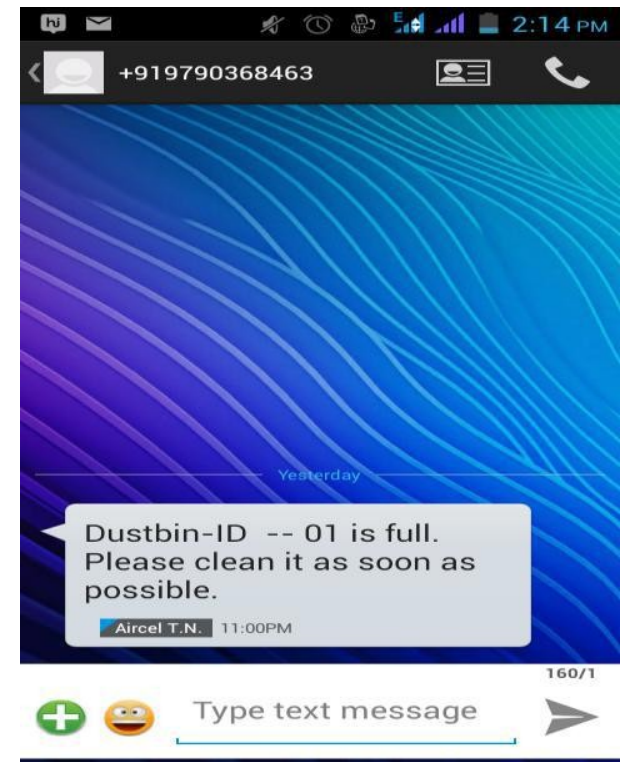

\section{Figure 2: Message sent to concerned person Paper}

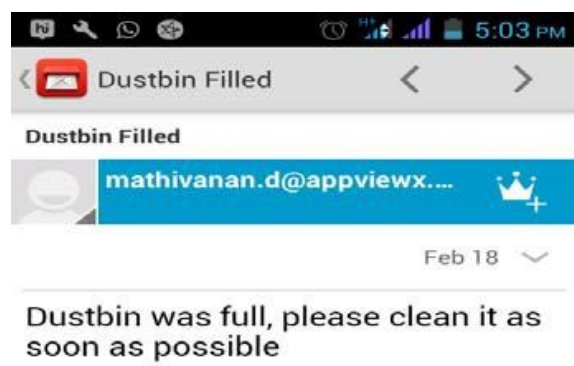

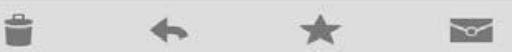

Figure 3: Mail sent to concerned person

\section{REFERENCES}

1) B. Vinothkumar1, K. Sivaranjani2, M.Sugunadevi3, V. Vijayakumar4 "IOT based Garbage Management System” International Journal of Science and Research (IJSR) ISSN (Online): 2319-7064, 2015

2) Kasliwal Manasi H, Suryawanshi Smitkumar, "A Novel Approach to Garbage Management Using Internet of Things for Smart Cities" International Journal of Current Trends in Engineering \& Research (IJCTER) e-ISSN 2455-1392 Volume
2 Issue 5, May 2016 pp. 348 - 353

3) Monika K A1, Nikitha Rao2, Prapulla S B3, Shobha G4. "Smart Dustbin-An Efficient Garbage Monitoring System" International Journal of Engineering Science and Computing, June 2016

4) Ms. Ankita Khedikar, Ms. Monika Khobragade, Ms. Neha Sawarkar. "GARBAGE MANAGEMENT OF SMART CITY USING IOT" International Journal of Research In Science \& Engineering e-ISSN: 2394-8299 Volume: 3 Issue:2 March-April 2017

5) Kannapiran Selvaraj, Dr. Arvind Chakrapani. "Smart Dustbin Monitoring System using LAN Server and Arduino" International Journal of Advances in Computer and Electronics Engineering Volume: 02 Issue: 04, April 2017, pp. $20-23$

6) Prof. S.A. Mahajan, Akshay Kokane, Apoorva Shewale, Mrunaya Shinde , Shivani Ingale, “ Smart Waste Management System using IoT" International Journal of Advanced Engineering Research and Science (IJAERS) [Vol-4, Issue-4, Apr- 2017] 